\title{
Doctoral Program Learning Module on Developing Leading Secondary School Teachers in Creative Thinking for Enhancement of Students' Learning Activities in Thailand
}

\author{
Chalard Chantarasombat ${ }^{1}$ \& Ekanun Sombatsakulkit ${ }^{2}$ \\ ${ }^{1}$ Faculty of Education, Northeastern University, Thailand \\ ${ }^{2}$ Faculty of Engineering, Northeastern University, Thailand \\ Correspondence: Chalard Chantarasombat, Faculty of Education, Northeastern University, Khon Kaen Province, \\ Thailand. Tel+6643222959-61.E-mail: chalard.cha@neu.ac.th; Email: ekanun@neu.ac.th
}

Received: November 5, 2020

Accepted: January 5, 2021

Online Published: January 7, 2021

doi:10.5430/ijhe.v10n3p138

URL: https://doi.org/10.5430/ijhe.v10n3p138

\begin{abstract}
The purposes of this study were to: 1) create and develop effective doctoral learning module on leading teachers development program to enhance critical thinking for students in secondary schools under the Office of Basic Education Commission, and 2) evaluate the developed module on its efficiency and effectiveness- its congruence of utility, possibility, and appropriateness, learning achievement of learners, learning retention, and the learners' satisfaction. Samples were 20 Doctoral degree students in Educational Administration and Development and Leadership program, Northeastern University, Khon Kaen Province, Thailand. Statistics used were percentage, mean, standard deviation, effectiveness index, and t-test. The results were: 1) The developed module on learning activity management of leading teachers in simulation situation had 9 Modules: (1.1) Survey of former experience (1.2) Collaboration in planning (1.3) The development of creative teacher conception (1.4) The application of thinking approach (1.5) Practice in classroom (1.6) Supervision, follow up, and evaluation (1.7) Feedback and reinforcement (1.8) Seminar for enhancing strength, and (1.9) Reflection learning. 2) The efficiency and effectiveness of the developed module were: (2.1) The efficiency of 86.53 (E1) /83.29 (E2) which were higher than the committed 80/80 standard, (2.2) The congruence of utility, possibility, and appropriateness were in the highest level $(\bar{X}=4.69, \mathrm{SD}=$ 0.42), (2.3) The effectiveness index was 0.7397 which meant students gained more knowledge of $73.97 \%$, (2.4) The students had significantly higher learning achievement after learning via the module at the level of 0.05 , (2.5) There was no significant differences of learning achievement between after learning and after learning for two weeks which mean the students' learning retention, and (2.6) The students had satisfaction on the developed module in the highest level $(\bar{x}=4.52, \mathrm{SD}=0.41)$.
\end{abstract}

Keywords: doctoral program development, leading teacher development, critical comparative analysis, creative thinking for enhancement, action learning

\section{Introduction}

\subsection{Rationale}

Knowledge could be changed as the dynamic. In the $21^{\text {st }}$ century, learners should adapt their learning from gaining knowledge to some necessary skills of cooperation and creating creative innovation. Consequently, learners should have chances to gain knowledge from various sources outside the classroom to practice analyzing, criticizing, deciding, solving problems, and creating new knowledge which occur in the integration outside classroom activities and inside classroom. Panich (2013) stated that teachers should not teach but advise their learners to have creative thinking, working together, creating and developing efficiency works. Teachers were the fundamental of changing especially those, who have prepared innovative learning conditions to create learning inspiration of learners via practice, have changed the teachers' role from teachers to tutors or coaches that could create learning inspirations.

In Thailand, Office of the Education Council, Ministry of Education, Thailand (2010) had done the research about the policy of developing teachers and educational personnel, the result showed the condition of learning management that though learners had been trained, they had some problems on low learning achievement and lacking of desirable characteristics on critical thinking and solving problems skills. Developing the innovation program for critical thinking 
enhancement to the secondary school leading teachers was a part of the subject Contrastive Study of Critical Comparative Analysis of Thai Education Management Global and Regional Society (ED41201) in semester 1, 2020 of doctoral students in Educational Administration and Leadership. We chose the part to be our content and had done our educational research and development on creating and developing an integrative learning module on the purpose to be used via Google classroom, which was an innovative learning condition of learners via flipped classroom techniques.

\subsection{Background}

Jonathan and Aaron's flipped classroom was the new techniques of learning management focused on teaching less learning more (Bergmann, \& Sams, 2012). Flipped classroom comprised online learning, online media, information technology, various communication, and doing activities in the classroom. It could support learners' self-practices in class, by using information technology and various communication, focusing on creating self-knowledge and individualized competency through self-paced. Moreover, they could have interaction with their peers and teachers in flipped classrooms. According to Panich (2013) and Weangsamoot (2009), it had to use various techniques which would be useful and necessary in developing teachers to have skills in learning management. Since enhancing skills of learning management creatively, understanding differences individually would be recognized because it caused the skills of designing learning management individually. We choose a learning module which has been an educational innovation technique used in flipped classrooms. It was the inspiration in learning management that supported learners to have analytical thinking. By using the module that was well systematically prepared, learners got their learning achievements. They have had their post-test scores significantly 0.1-0.5 higher than their pre- test one (Suda, 2005; Donbundit, 2008; Inruangsri, 2011; Paphaphasid, 2018; Chantarasombat, Udombunyanupab, \& Kenchaiyawong, 2018). Moreover, their satisfaction was in the highest level (Hasakool, Chianchana, \& Stirayakorn, 2016; Krongtanoen, 2016; Chantarasombat, Udombunyanupab, \& Kenchaiyawong, 2018; Chantarasombat, \& Meekhamtong, 2020)

In semester 1, 2020, we had started the learning module for doctoral students in Educational Administration and Leadership at Northeastern University, Khon Kaen, Thailand, by studying elements and factors including the current and desirable condition of Thai learning management in enhancing the critical thinking of the secondary school teachers before creating the program by using google classroom technique. We used 5 experts and 2 pre-test groups who were not our research population to evaluate our module. Their feedback had been used to develop the module for improving learning and teaching focusing on participating between teachers, administrators, and academic persons before offering the module to the doctoral students.

\subsection{Research Questions}

1) How could the learning module of leader-teacher in learning management for enhancing critical thinking of the secondary school teachers, in the Subject of Contrastive Study of Critical Comparative Analysis of Thai Education Management Global and Regional Society (ED41201), be created and developed?

2) How much did its achievements be evaluated on: it's appropriate, possible, related, and useful by experts, on the students effectively at 80/80, on index of its effectiveness, on the learning achievement, on the learning retention, and on students' satisfaction of the module?

\subsection{Research Objectives Are as Follows}

- To study the factors of learning management in enhancing the critical thinking of the secondary school teacher 1.4.2 To investigate the current and desirable condition of learning management in enhancing critical thinking of the secondary school teachers

- To create the program of leader-teacher in learning management for enhancing critical thinking of the secondary school teachers by using google classroom technique

- To develop the program of leader-teacher in learning management for enhancing critical thinking of the secondary school teachers in the Subject of Contrastive Study of Critical Comparative Analysis of Thai Education Management Global and Regional Society (ED41201) for students by using google classroom technique

- To evaluate the quality of the program of leader-teacher in learning management for enhancing critical thinking of the secondary school teachers in the Subject of Contrastive Study of Critical Comparative Analysis of Thai Education Management Global and Regional Society (ED41201) for students by using google classroom technique 1.4.6 To compare pre and posttest scores of the learning achievement of the students who use the program of leader-teacher in learning management for enhancing critical thinking of the secondary school teachers in the Subject of Contrastive Study of Critical Comparative Analysis of Thai 
Education Management Global and Regional Society(ED41201) for students by using google classroom technique

\subsection{Research Conceptual Framework}

The development of the learning module and the conceptual framework was determined by the authors with experts' evaluations. The innovation of the learning module consisted of 9 learning sub-modules including 1: surveying the former experience, 2: planning, 3: creating comprehension, 4: applying the idea, 5: practicing in class, 6: supervision and assessing, 7: giving feedback and giving support, 8: seminar, and 9: giving reflection. As shown in Figure 1.

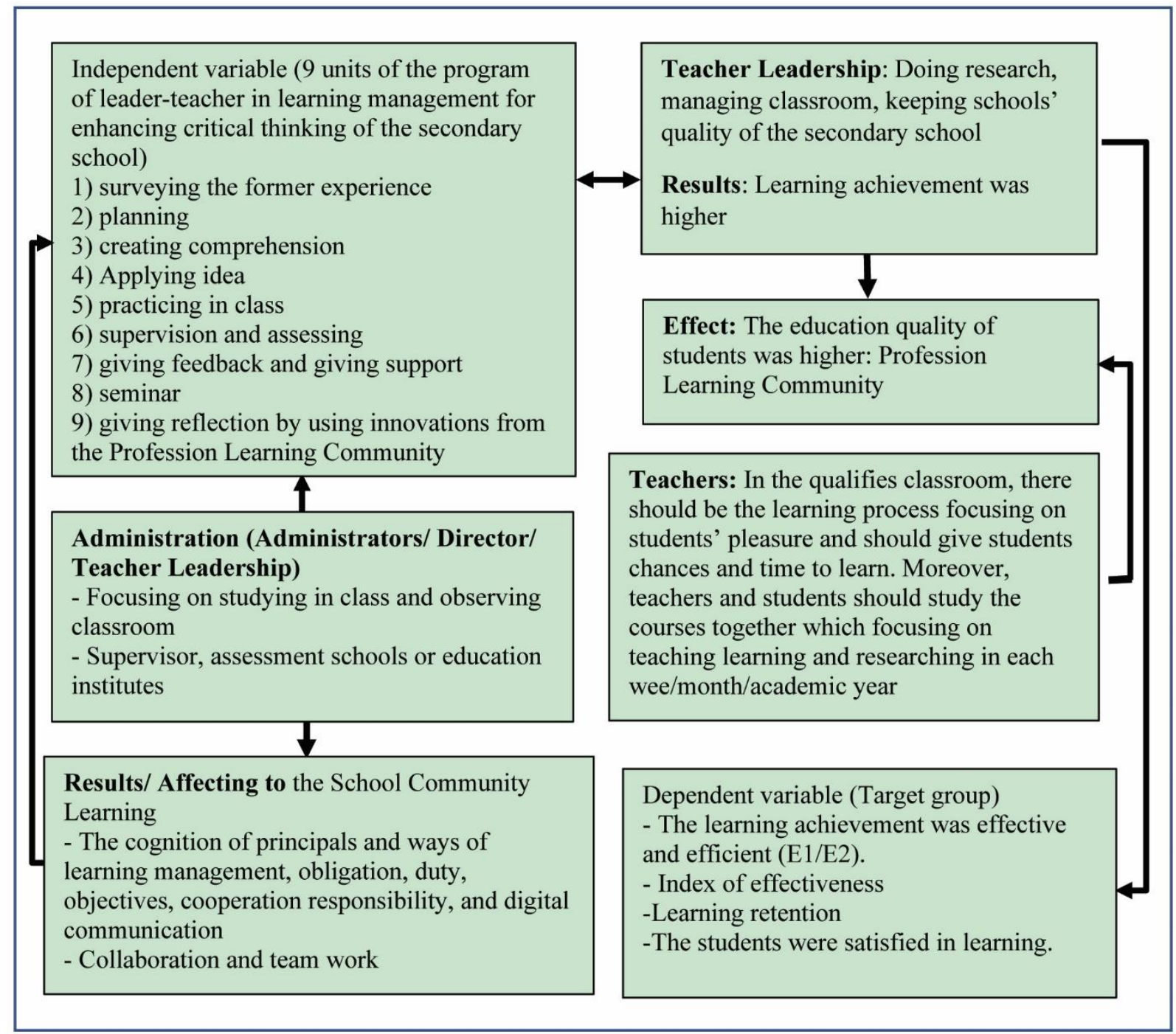

Figure 1. Conceptual Framework of the study of developing the program of leader teacher in learning management for enhancing critical thinking

\section{Research Methodology}

\subsection{Construction and Development of Research Instruments}

Steps of setting and/or developing the research instruments could be divided into 3 parts: 1) To create and develop the learning module, 2) To create and develop the learning achievement tests, and 3) To create and develop the satisfaction questionnaires

\subsubsection{To Create and Develop the Learning Module as Follow}

1) Brainstorming and planning for developing a learning module for doctoral students in Educational Administration and Leadership, Northeastern University, Khon Kaen, Thailand.

2) Investigating concepts, theories, principles, policies, and strategies of educational administration on learning in 
$21^{\text {st }}$ century. Moreover, researchers analyzed the basic information, the condition, problems of learning management, and developing teachers to identify issues of developing. Furthermore, the researchers investigated the scope of the study, theories, and related review in learning management for enhancing critical thinking of the secondary school teachers by criticizing factors occurring. The questionnaires were used to enhance the secondary teachers which could support them to get the rewards for the innovation of learning management in the northeastern of Thailand. The data from 136 people who answered the questionnaire with 9 modules and factors were examined by 5 experts again. After that, all factors were combined and defined to find the detail to form the program and documents presented to 5 experts later.

3) Finding the relation of the content and learning module. Researchers defined vision of the

module and created its planning structures to achieve the objectives of the program and to enhance the people in the experiment, had vision, and had critical thinking in steps of learning management. There were studying, designing, developing and using the module. The module instrument included facilities, and a guide book. The guide book could help users understand easily and it was examined by the experts. Beside these, there were assessing and examining. The fundamental concepts to define the schedule of the module included concepts, participatory learning, advising, practicing, supervision, suggestion, giving feedback, and the theories related to the nature of teachers. The result from the experts showed that the planning module was appropriate, possible, related, and useful in the highest level.

4) Offering 9 units of the learning program to the groups who were not the research population; 1) group of 5 people, then improved in the illustrations and recorded, and 2) group of 9 people, including the doctoral degree students in Education Administration 1 in semester 2, 2019. The result showed that the effectiveness was at 83.45/80.56 which was similar to the setting standard.

\subsubsection{To Create and Develop Learning Achievement Test as Follow}

1) Investigating theories, principles, and concepts to create the achievement test on the theory of Sri sa-ard (2010).

2) Multiple choices were used to create the achievement test with 4 choices, including 40 questions and the test comprised only 30 questions.

3) After preparing the test, it was presented to the experts to evaluate and find relation between the behavioral objectives. The criteria of grading the test were 1) +1 when the test was assessed by the behavioral objectives, 2) 0 when the test was not clear from behavioral objectives, and 3) -1 when the test was not assessed by the behavioral objectives.

4) Analyzing the data to find the index of effectiveness between the questions of the test and the behavioral objectives using IOC (Pattiyatanee, 2008). If the IOC of the test was at 0.5-1.00, the test was reliable.

5) After finding IOC, the test was used with 23 master degree students, the major of Education Administration, in the subject of Seminar for Educational Administration in order to observe the students' behavior during doing the test, how did they spend their time doing the test, how did they understand the test, and how did they answer the questions.

6) After finishing the test, the scores of the test were calculated to find the difficulty $(\mathrm{P})$ and discrimination of each question. After calculating, the result showed that $\mathrm{P}$ of the test was at 0.40-0.80 and the discrimination of the test was at $0.20-0.60$. After finding the reliability of the test, it was at 0.84 . Then the test could be used with the research.

\subsubsection{To Create and Develop Satisfaction Questionnaires, Comprised of 8 Parts With 45 Questions as Follow}

1) Investigating theories, principles, and concepts on the satisfaction of Suntrayuth (2008).

2) Studying techniques of doing the questionnaire (Sri sa-ard, 2010).

3) Educating and creating questionnaires of satisfaction based on the objectives using 5 rating scales.

4) Presenting the questionnaire to the experts to assess the relation between the questions and the objectives. The criteria were the same as the achievement test.

5) Analyzing the data to find the index of effectiveness between the questions of the questionnaire

and the behavioral objectives using IOC (Pattiyatanee, 2008). The IOC of the questionnaire was at 0.80-1.00. The experts suggested that language usage should be arranged by following the grammar correction, the sentences 
should be clear, and if there were some sentences that are similar in meaning, those sentences should be concluded and made only one sentence.

6) Using the questionnaire with the groups who were not the research population, including 30 master degree students of Education Administration, and the group of teachers and supervisors in Khon Kaen Primary Education Service Area Office. The results would be analyzed to find discrimination $\left(\mathrm{r}_{\mathrm{xy}}\right)$ on each question during 0.32-0.86 and the questionnaires would be analyzed to find the reliability with the $\alpha$-Coefficient using Cronbach alpha technique (Sri sa-ard, 2010). The reliability was 0.96 .

\subsection{Data Collection and Analysis}

1) The efficiency and effectiveness of the learning module was analyzed by using the Mean and Percentage of Brahmawong (2013). The efficiency was searched for by using $E_{1} / E_{2}$. Formula as follows:

$$
\begin{aligned}
& E_{1}=\frac{\sum \mathrm{X} / \mathrm{N}}{A} X 100 \\
& E_{2}=\frac{\sum \mathrm{F} / \mathrm{N}}{B} \times 100
\end{aligned}
$$

The effectiveness index of the learning module was analyzed by using the following E.I. formula.

Effectiveness Index (E.I.) $=$ The sum of the post-test score - the sum of pre-test score

$$
\text { (Student Number X Full Score) - The sum of the pre-test score }
$$

2)The student's knowledge and learning retention data was collected by pre-test and post-test learning scores from the learning achievement test while the learning retention had to be collected after the post-test which was performed 2 weeks later. Comparison of the learning achievement of the learning module was analyzed by mean values of t-test (Dependent) comparative analysis between pre-score and post-score (Sri sa-ard, 2010).

3) The satisfaction on the learning module data was collected by using the satisfaction questionnaire. It was analyzed by using the Mean value $(\overline{\mathrm{X}})$ and Standard Deviation (S.D.) for measuring the satisfaction level.

\section{Results}

\subsection{The Factors of Critical Thinking of the Secondary School Teachers Comprised of 10 Factors}

1) teachers prepared various learning activities, 2) teachers presented motivated activities, 3) teachers offered learning activities in different places, 4) teachers offered learning activities emphasizing on child center, 5) teachers used technology in learning management, 6) teachers offered activities related to daily life, 7) teachers used innovation in learning activities, 8) the activities were cooperated with the community, 9) the activities were emphasized on teaching moral, and 10) the activities were assessed and evaluated. The study found that the current condition of learning management for enhancing critical thinking of the secondary school students was at moderate level. When considering each factor, the experts agreed with the teachers about preparing various learning activities and using technology in learning management. The desirable condition was at the highest level, too. As shown in Figure 2. 


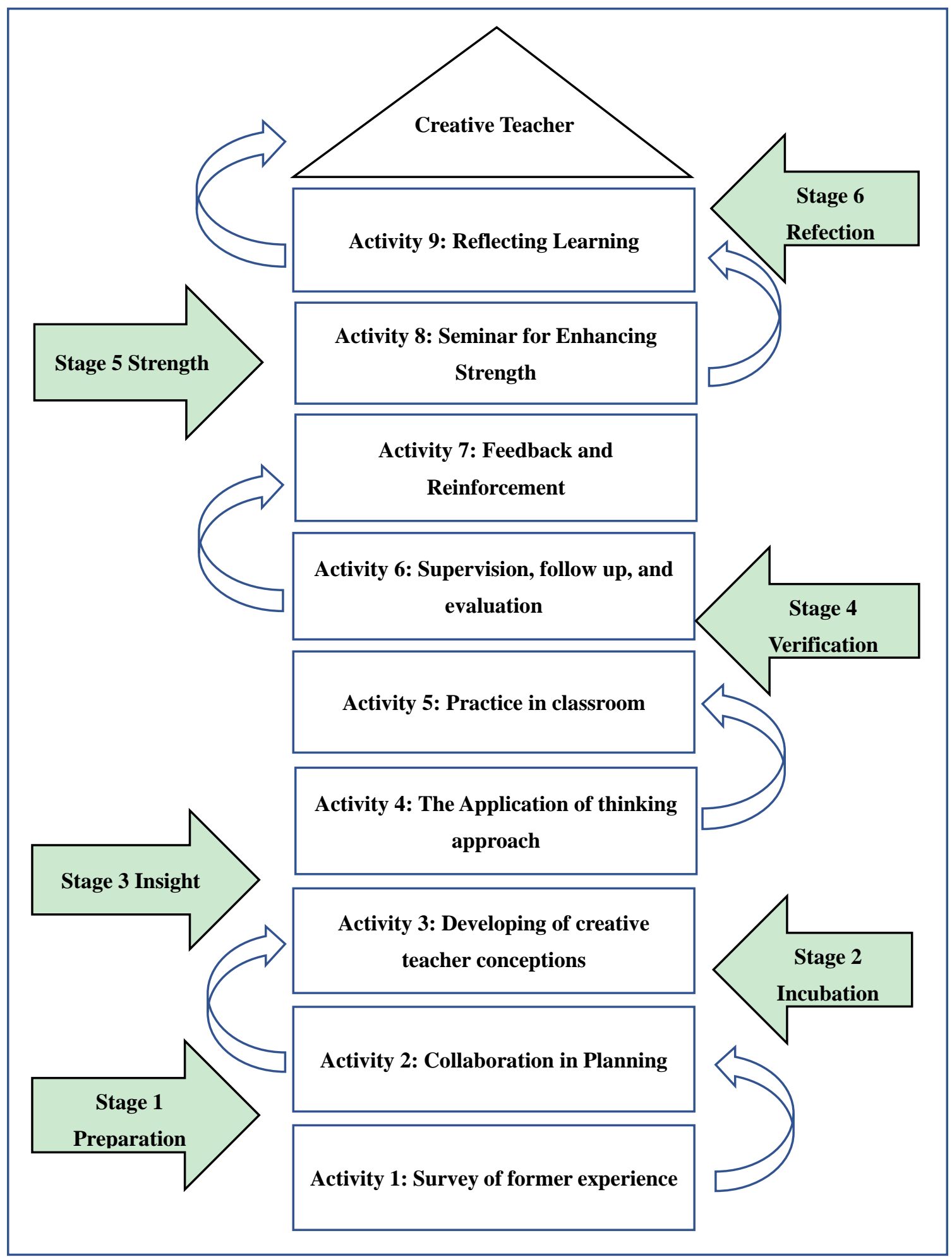

Figure 2. Creative Module of Teacher Leadership Program for Learning Management in Enhancing the Critical Thinking of the Secondary School Teachers: Critical Comparative Analysis of Thai Education Management Global and Regional Society (ED41201) students

The program in learning management for enhancing critical thinking of the secondary school students including: 1) the principal of the program, 2) the objectives of the program, 3) the goal of the program, 4) the content of the program development. The content included into 9 modules: 1) the survey of experiences, 2) the planning, 3) the concepts, 4) 
the applied concepts, 5) the classroom implementation, 6) the supervision, monitoring and evaluating of the study, 7) the feedback and reinforcement, 8) the seminar for strengthening, and 9) the presentation at the academic conference. The final parts of the module focused on doing activities outside the classroom. The researchers defined activities on learning by doing under advising and helping continuously. The learners who participated must have plans, and review the principals from the beginning to face with real practicing. It meant that there were advisors who gave advice, taught, and gave feedback continuously. This process could make the understanding. The treatment included training, and self-development which included 6 steps; 1) preparation, 2) training, 3) understanding thoroughly, 4) verifying and evaluating, 5) strengthening, and 6) giving feedback. The results from the experts' evaluation showed that the benefits, possibilities, correcting, and suitability at the highest level $(\overline{\mathrm{x}}=4.69, \mathrm{SD}=0.42)$.

\subsection{The Results from the Research about the Module Found Its Achievement as Follows}

1) The program had the efficiency of the process for the learning outcome (E1 / E2) at 86.53/ 83.00 which was higher than the criteria at $80 / 80$.

2) The effectiveness index for the program was at 0.7397 which explained that students gain higher knowledge $73.97 \%$.

3) The students who were taught by the module gained their learning post-test score higher than their pre-test scores significantly at .05. After teaching, their learning retention data showed the students gained similar scores from the posttest and after 2 weeks of teaching. It was clear that students' learning retention scores by the module was stable.

4) The students' satisfaction from the module was at the highest level ( $\overline{\mathrm{x}}=4.52, \mathrm{SD}=0.41$ ).

\section{Discussions}

The evaluation results from the experts showed the success of the learning module at high level $(\overline{\mathrm{X}}=4.69)$ and when finding the effectiveness of the program found that the program was efficient at 86.53/83.29. It was because the module was well developed systematically through theories, researching, and examining by experts which supported its efficiency related to Suda (2005); Donbundit (2008); Inruangsri (2011); Paphaphasid (2018) and Chantarasombat, Udombunyanupab, \& Kenchaiyawong (2018); Chantarasombat, \& Meekhamtong (2020) that with the module that was well systematically prepared, learners could get their learning achievements from its effectiveness.

The program could enhance understanding, attitude, and skills of learning management. The comparison of learning management before and after using the program found that learners had the skills of learning management higher than before using the module significantly at .05 . Students who studied by the program were effectively at $85.539 /$ the effectiveness of the result was 83.29 higher than 80/80. The index of effectiveness was higher $73.97 \%$ and had retention in learning after studying 2 weeks. It was because the module had been improved several steps in the process of research and development, then was standardized by experts. The module was designed to have relearning for students starting from theories to practices. Beside this, the module focused on doing activities outside the classroom, on learning by doing under advising and helping continuously. It meant that there were advisors who gave advice, taught, and gave feedback continuously. This process could make the understanding, the knowledge was retention and comprehended deeply in learning management.

\section{Recommendations}

\subsection{Recommendations for Application and Development}

The administrators and those, who were involved with the development of quality of education and teachers in the secondary education service area and in other educational institutes, should enhance the use of the designed program for creative thinking enhancements to support learning activity management in secondary schools. The module was a standard one because it was systematically approved by the experts and experimented to be authentically implemented. Beside this, it was revised and edited several times to be an effective module for developing teachers to be knowledgeable and be skillful on managing learning activity with creativity.

For implementing the designed module, for learning management in enhancing the critical thinking of the secondary school teachers, most effectively according with the objectives of the program, it should use the module continuously in both theoretical part and practical part in which the teachers could practice their teaching in real situations. The process on the module would help the teachers to participate in training. They could be capable of implementing their knowledge and experience form their learning to the real practice systematically. Furthermore, the evaluations and follow-up sessions were also needed in order to be the teachers' suggestions and guidelines for teachers in every stage of the module so they could apply the obtained knowledge for their effective and confidently teaching. 
Process of learning activities in the module had focused on practicing to enhance learning management skills for teachers. On applying the module, it needed to emphasize on the teachers participating in the development program to follow every stage specified. The support from their school administrators, school supervisors and their teachers' colleagues could enhance the teachers' knowledge, understanding, and positive attitude as well as their leadership skill in learning management according to the objectives of the program.

The Office of the Education Commission should set the national policy to promote and support schools for developing teachers' skill for classroom management to enhance students' critical thinking. They should also promote model teachers' roles to be teachers who taught and learned with students, to be teachers who know and have done research works to achieve the goals effectively. Thai classroom management to enhance the secondary school students' critical thinking, both government and private schools, should be integrated with Google classroom and started from the schools with readiness.

\subsection{Recommendations for Future Research}

This educational research and development was conducted to study the creation and development of enhancing creative thinking in teachers' learning management. There should be research on developing teachers' creative thinking in other aspects of their tasks, such as the development of teachers' critical thinking on classroom research, on doing projects, on providing students' assistance, or on designing teaching materials, etc.

This study had emphasized on the development of creative thinking for teachers' skill of classroom management by using development modules. There should be the study to enhance teachers' critical thinking through other learning techniques, such as training, school-based training, or workshop in order to compare those techniques for learning activity management which could appropriately provide knowledge of development.

The effectiveness of the module was examined by comparing the knowledge and understanding, skill and attitude of teachers in learning activity management toward creative learning management before and after using the module. The suggestion for the further research was to investigate whether the knowledge and understanding, skill and attitude of teachers were related to creative learning activities.

\section{Conclusion}

The learning module on developing the innovation program for critical thinking enhancement to the secondary school leading teachers was a part of the subject Contrastive Study of Critical Comparative Analysis of Thai Education Management Global and Regional Society (ED41201) was created and developed as an educational research and development. With well-organized and revised, it responded to the objectives of the doctoral program on creating knowledge on enhancing critical thinking with students' comprehension, good attitude and skills for managing learning activities creatively.

\section{Acknowledgment}

Deeply thanks the Dean of the Faculty of Education and the President of Northeastern University for supporting lecturers in both under graduate, Graduate and Postgraduate Curriculums, Administration and Leadership in Education program to develop potential to learn with learners and staff as well as to conduct the research and development in order to develop learning package innovation to be an effective learning model in according with the needs of the users and stakeholders.

\section{References}

Bergmann, J., \& Sams, A. (2012). Flip your classroom: Reach every student in every class every day. ASCD.

Brahmawong, C. (2013). Developmental testing of media and instructional packages. Silpakorn Education Research Journal, 5(1), 7-16.

Chantarasombat, C., \& Meekhamtong, P. (2020). The Development of Leader Teachers Development Program in Learning Thai Management for Enhancing Critical Thinking of Students in Secondary research and development for the implementation of development program to develop teachers to be Schools in Educational Administration Seminar Course for Master Degree Students Majoring in Education Administration. Educational Research, 11(1), 10-20. https://doi.org/10.5430/wje.v10n3p19

Chantarasombat, C., Udombunyanuparb, N., \& Kenchaiwong, N. (2018). Development of innovation enhances learning achievement of educational schools in Northeastern Thailand under the Office of the Basic Education Commission. Journal of Education, Mahasarakham University, 12(2), 54-69. 
Donbundit, P. (2008). Developing of Chemistry module for university level by cycle of innovation. [Doctoral dissertation, Srinakharinwirot University]. http://thesis.swu.ac.th/swudis/Sci_Ed/Piyarat_D.pdf

Hasakool, R., Chianchana, C., \& Stirayakorn, P. (2016). The development of administration on short training course modules for education institutes under the Office of Vocational Education Commission. Technical Education Journal King Mongkut's University of Technology North Bangkok, 7(2), 52-60.

Inruangsri, S. (2011). Developing of Thai lives and culture module for the vocational students at Automotive Industry Technician College. [Master's thesis, Phranakhon Si Ayutthaya Rajabhat University].

Krongtanoen, P. (2016). Development of Mathematics learning modules on sequence. [Master's thesis, Chiangmai University]. https://tdc.thailis.or.th/tdc/

Office of the Education Council, Ministry of Education, Thailand. (2010). Research and development of teacher development policies and educational persons. Office.

Panich, V. (2013). Teachers for learners in flipped classrooms. S. R. Printing.

Paphaphasid, A. (2018). Education innovation for doing research in class by creating learning material by yourselves and giving advice in class. King Mongkut's University of Technology North Bangkok.

Pattiyatanee, S. (2008). Educational assessment (6th ed.). Prasan Printing.

Sri sa-ard, B. (2010). Basic research (8th ed.). Suveeriyasas.

Suda, S. (2005). Developing of industrial control system for applying censor equipment for Diploma in Electrical Technology at Saraburi Technical College. [Master's thesis, King Mongkut's University of Technology Thonburi. https://tdc.thailis.or.th/tdc/

Suntrayuth, T. (2008). Reformed management: Research theory and practice in Education. Neatikul Printing.

Weangsamoot, V. (2009). A development of a learning organization development model for Mathematics teachers in the first-and second-class intervals. [Doctoral dissertation, Mahasarakham University]. https://tdc.thailis.or.th/tdc/

\section{Notes}

Note 1. Appendix: Questionnaires for Student Satisfaction on Teacher Quality and Learning Support, Faculty of Education, Northeastern University 


\section{Appendix}

\section{Questionnaire for Student Satisfaction on Teacher Quality and Learning Support, Faculty of Education, Northeastern University, First Semester / 2020}

\section{Explanation}

1. The questionnaire aims to survey the level of students' satisfaction with the quality of teaching of teachers and learning support.

2. This questionnaire has 3 sections. Please answer all sections.

3. Answering this questionnaire will not affect students' learning and teaching. The Faculty of Education will keep students' responses confidential. But will present the overall assessment results to be a guideline for the development and improvement of teaching and learning to be more appropriate and effective.

4. Please mark $\checkmark$ in the box that is most realistic for the benefit of teaching quality assessment.

\section{Section 1 General information of respondents for the assessment}

1. Sex $\square$ Male $\square$ Female

2. Faculty

3. Student Level $\square$ Bachelor degree $\square$ Master's Degree $\square$ Ph.D. $\square$ Others

4. Course assessed by students Course ED 41201 Critical Comparative Analysis of Thai Education Management at Global and Regional Society

5. Instructor Associate Professor Chalard Chantarasombat, Assistant Professor Chaiyuth Sirisuthi and Dr. Ekanun Sombatsakulkit

Section 2 Satisfaction with the teaching quality of teachers and learning support

\section{Explanation}

1. Practical Sections answer every question except question 2.

2. Theoretical Sections, answer every question except question 3.

3. Theoretical and Practical Sections, answer every questions.

\begin{tabular}{|l|l|l|l|l|l|}
\hline \multicolumn{2}{|c|}{ Subject } & \multicolumn{3}{c|}{ Satisfaction Level } \\
\cline { 2 - 6 } & Highest & High & Medium & Low & Lowest \\
\hline 1. Subject matter & & & & & \\
\hline $\begin{array}{l}\text { 1.1 Consistency of subject with the objectives of the learning } \\
\text { course? }\end{array}$ & & & & & \\
\hline $\begin{array}{l}1.2 \text { Is the content significant and beneficial to the actual use? } \\
\text { 2. Teaching skills of teachers (Assessing the theoretical } \\
\text { courses) }\end{array}$ & & & & & \\
\hline 2.1 Step by step instructions that are easy to understand? & & & & & \\
\hline $\begin{array}{l}\text { 2.2 Clear answers and provide examples to explanations for } \\
\text { clearer understanding? }\end{array}$ & & & & & \\
\hline 2.3 Apply modern research results or information in teaching? & & & & & \\
\hline 2.4 Bridge the lessons to practical implementations in real world & & & & & \\
\hline
\end{tabular}




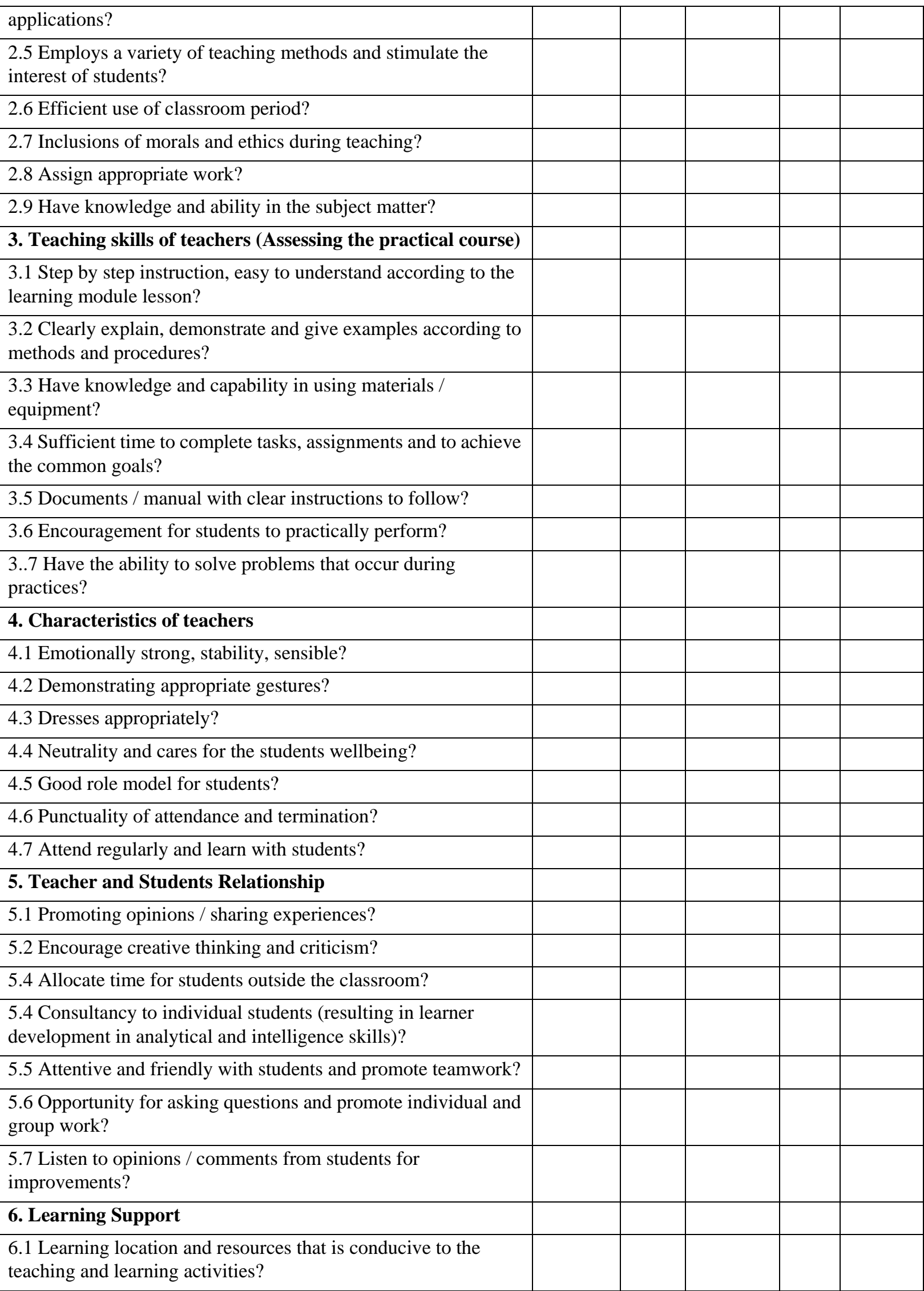




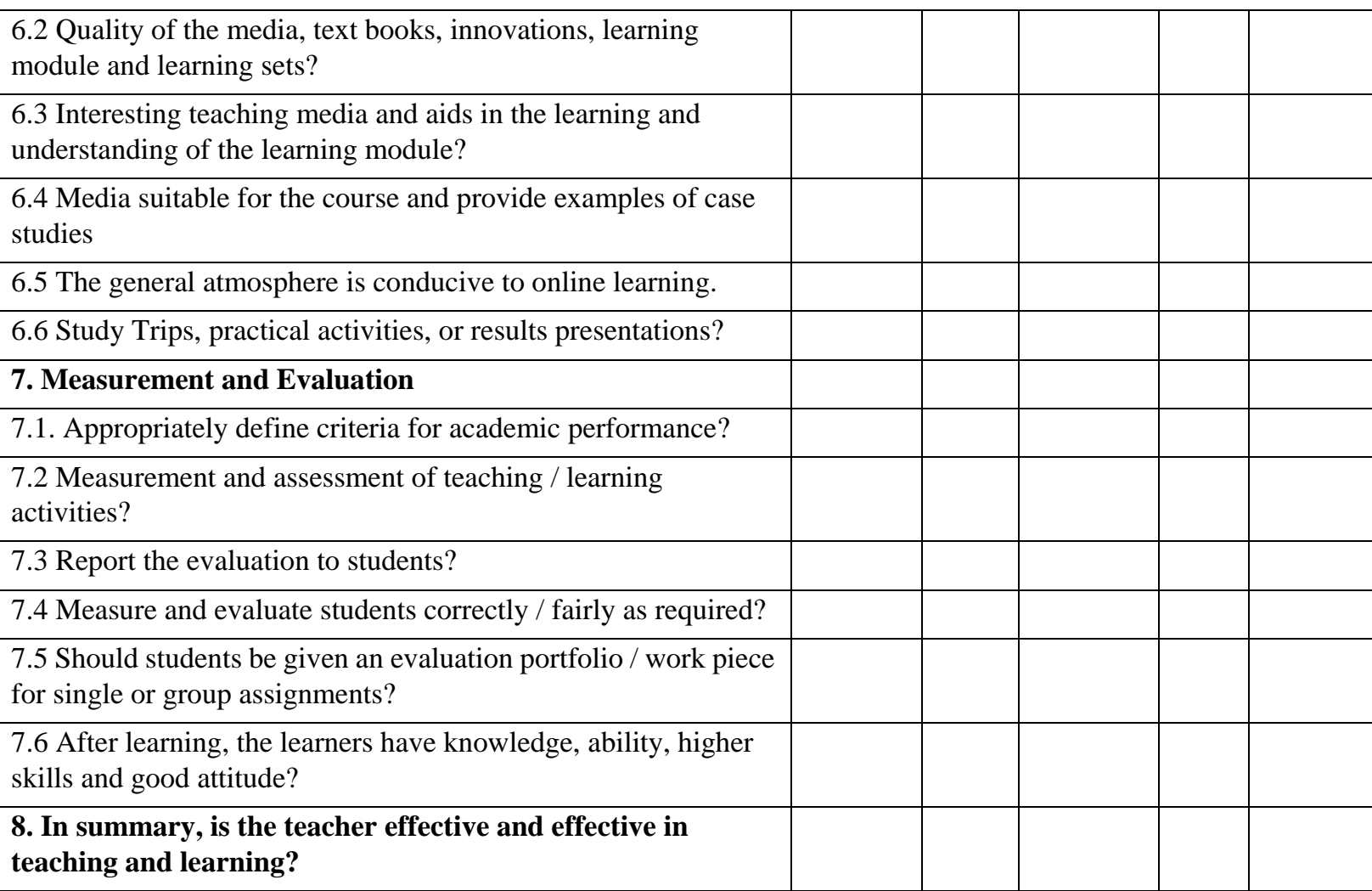

Section 3 Additional recommendations (strengths to develop and meet standards or weaknesses for further improvement of teaching and learning)

Thank you to all respondents for your cooperation.

\section{Copyrights}

Copyright for this article is retained by the author(s), with first publication rights granted to the journal.

This is an open-access article distributed under the terms and conditions of the Creative Commons Attribution license (http://creativecommons.org/licenses/by/4.0/). 